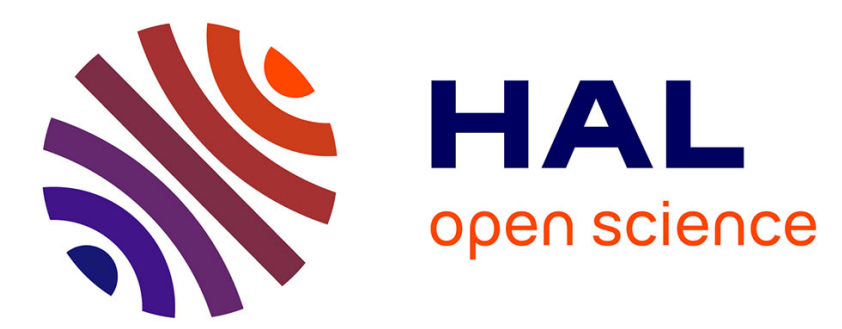

\title{
Oxidative drying properties of a helmet pentadentate phthalocyanine-derived iron(III) complex
}

\author{
L. Dubrulle, R. Lebeuf, V. Nardello-Rataj
}

\section{To cite this version:}

L. Dubrulle, R. Lebeuf, V. Nardello-Rataj. Oxidative drying properties of a helmet pentadentate phthalocyanine-derived iron(III) complex. Progress in Organic Coatings, 2019, 131, pp.364 - 370. 10.1016/j.porgcoat.2019.03.007 . hal-03486960

\section{HAL Id: hal-03486960 \\ https://hal.science/hal-03486960}

Submitted on 20 Dec 2021

HAL is a multi-disciplinary open access archive for the deposit and dissemination of scientific research documents, whether they are published or not. The documents may come from teaching and research institutions in France or abroad, or from public or private research centers.
L'archive ouverte pluridisciplinaire HAL, est destinée au dépôt et à la diffusion de documents scientifiques de niveau recherche, publiés ou non, émanant des établissements d'enseignement et de recherche français ou étrangers, des laboratoires publics ou privés.

\section{다)(1) $(5$}

Distributed under a Creative Commons Attribution - NonCommerciall 4.0 International 


\title{
Oxidative Drying Properties of a Helmet Pentadentate Phthalocyanine-derived Iron(III) Complex
}

\author{
L. Dubrulle, ${ }^{a}$ R. Lebeuf, ${ }^{a,}$, V. Nardello-Rataj ${ }^{\mathrm{a}, ~}{ }^{,}$ \\ ${ }^{a}$ Univ. Lille, CNRS, Centrale Lille, ENSCL, Univ. Artois, UMR 8181 - UCCS Unité de Catalyse et \\ Chimie du Solide, F-59000 Lille, \\ *Corresponding authors.Email Addresses: raphael.lebeuf@univ-lille.fr and veronique.rataj@univ- \\ lille1.fr
}

\begin{abstract}
The structure of a hexaisoindoline iron(III) complex reported in 1962 was corrected as the one of a recently described helmet phthalocyanine-like iron(III) complex. Accordingly, its catalytic activities were compared to commercial $\mathrm{Co}(\mathrm{II})$ and $\mathrm{Fe}(\mathrm{II})$ driers towards the oxidation of bulk FAMEs through oxygen uptake measurements and by ATR-FTIR spectroscopy, as well as its ability to decompose methyl linoleate hydroperoxides. It is shown that the phthalocyanine-like iron(III) complex presents higher catalytic performances at low concentrations and under mild conditions of temperature and pressure, both on the overall oxidation process and on the decomposition steps of the drying chemical process. The efficiency of the phthalocyanine-derived iron(III) complex was confirmed by the drying of an alkyd resin emulsion and a satin white paint formulation which exhibits a very good hardness and a low yellowing of the film.
\end{abstract}

Keywords: Oxidation; Hydroperoxides; Iron catalyst; Alkyd resins; Fatty acid methyl esters 


\section{Introduction}

As a general trend, iron-based catalysts appear as the most relevant substitutes to other metals for oxidation chemistry, being generally perceived as safe and cheap catalysts [1,2]. A key point concerns the ligand design to tune the reactivity and selectivities [3,4], without losing sight of an easy access for practical applications. One of them concerns the chemical drying of alkyd resins, i.e. the oxidation of the unsaturated lipidic part of a polyester resin, providing hydroperoxides as primary oxidation products. Their decomposition into radicals such as $\mathrm{RO}^{\bullet}$ and $\mathrm{ROO}^{\circ}$ results in the film curing through crosslinking [5,6]. In addition to the effectiveness of such catalyst called driers or siccatives, the yellowing of the film coating can be an additional problem to solve in case of white paints applications. Actually, the most common drier is the cobalt (II) bis(2-ethylhexanoate) salt 1-Co(II)

(Figure 1), which is however suspected to be carcinogenic [7]. Anticipating its future ban as an additive in paints, finding alternatives to cobalt-based driers has become a real challenge [8], especially in a revival context for alkyd paints due to their low VOC generation (waterborne paints) and bio-sourced composition [9]. Whereas the use of enzymes constitutes an interesting approach [10], more efforts are devoted to the use of other transition metals such as iron and manganese [11], as well as vanadium in a lesser extent at that time [12]. Their chelation on polymers [13] or the addition of nitrogen ligands such as bipyridine or phenanthroline on simple carboxylates or acetylacetonates precursors improve their performances [14-17]. Other additives like salen ligands [18] or ascorbic acid with iron $[19,20]$ can also be used, but development of well-defined complexes can procure even more active catalysts. For instance, Van der Linde et al. have proposed a binuclear manganese complex (known as MnMeTACN) which exhibits a similar activity to commercial cobalt-based driers towards the oxidation of ethyl linoleate [21-23]. Concerning iron chemistry, Vesely et al. have developed acyl ferrocenes as new driers for solvent-born alkyd resins [24]. All studied ferrocenes derivatives were found to be active catalysts for the drying of alkyd resins with hardness film performances reaching those obtained with cobalt derivatives. In 2012 and 2013, the OMG Additives Limited and PPG Companies patented a divalent iron complex associated with nitrogen pentadentate "bispidine" ligands for the coating application, commercialized by OMG Borchers, named Borchi® OXY-Coat (2-Fe(II), Figure 1) $[25,26]$. This catalyst was primarily developed for the bleaching of tomato stain (oxidation 
of carotene) by the Unilever Company, and as a particularly active catalyst, they studied it for the chemical drying of alkyd coatings [27].
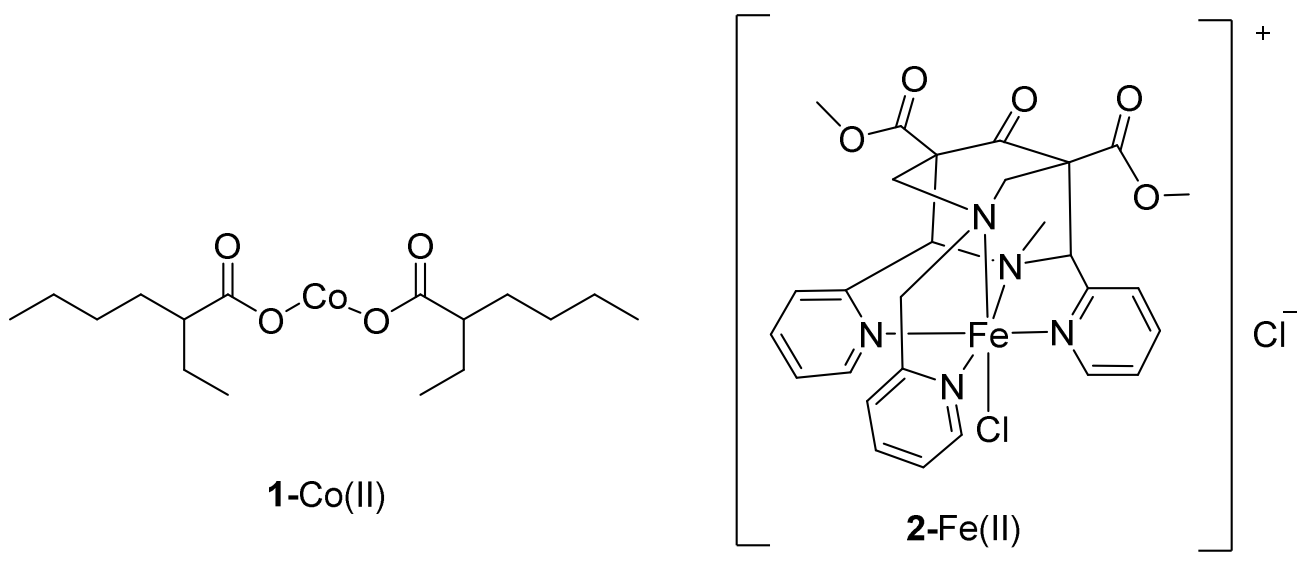

Figure 1. Chemical structures of commercial 1-Co(II) and 2-Fe(II) driers.

In the present work, we have reinvestigated a hexaisoindoline iron(III) complex 3-Fe(III) (Figure 2) patented in 1962 by Kaufmann as a potential drying agent of alkyd resins, who described its synthesis in a single step by condensation of phthalic anhydride, urea and ammonium iron(II) sulfate [28]. Based on elementary analysis and IR spectroscopy, such hexacoordinated iron(III) structure was proposed at that time. In 1964, the author showed that this complex could provide well-formed films on drying oils and unsaturated polyester substrates within acceptable drying times [29,30], better than porphyrin and phthalocyanine complexes, which were also studied latter by Santhanam [31]. In 1982, Kaufmann's work was revisited by Slosar et al. who improved the yield of the synthesis by replacing phthalic anhydride with 1,3-diiminoisoindoline, and ammonium iron(II) sulfate with Mohr's salt of $\mathrm{Fe}(\mathrm{III})$ [32]. They also studied the activity of the product for the drying of polyester substrates in comparison to cobalt driers but the physical performances such as the film adhesion were lower $[33,34]$.

In this study, we will first show that the proposed hexaisoindoline iron(III) complex 3-Fe(III) structure corresponds in fact to a recently described pentadentate phthalocyanine-like iron(III) "helmet" complex (4-Fe(III), Figure 2). Its ability to catalyze the oxidation of bulk sunflower FAMEs and an alkyd resin emulsion was compared to the commercially available 1-Co(II) and 2-Fe(II) driers. Also, 
the kinetics of the decomposition of methyl linoleate hydroperoxides in their presence were compared since it is an important pathway for radical generation. Finally, an application test was performed on a white alkyd-based satin coating to show that good hardness can be obtained with low yellowing.

\section{Results and discussion}

\subsection{Synthesis and structural reassignment of 3-Fe(III) into 4-Fe(III)}

The synthesis of $\mathbf{3}-\mathrm{Fe}(\mathrm{III})$ was done according to Slosar et al. procedure [30,32] (see experimental part). The product obtained by precipitation was first analyzed by mass spectrometry, which revealed a different structure to the proposed one and has been assigned to a helmet pentadentate phthalocyaninelike 4-Fe(III) complex (Figure 2 and Figure 3). In fact, such structure was recently obtained in 2006 by McGaff et al. through another analogous way by polycondensation of 1,2-dicyanobenzene in methanol at $130^{\circ} \mathrm{C}$, and fully characterized at that time thanks to X-ray crystallography after a first silica gel chromatography purification [35]. Application as catalyst for the epoxidation of olefins with $\mathrm{H}_{2} \mathrm{O}_{2}$ was proposed after by Sorokin et al. [36] whereas McGaff studied the oxidation of primary and secondary alcohols [37].

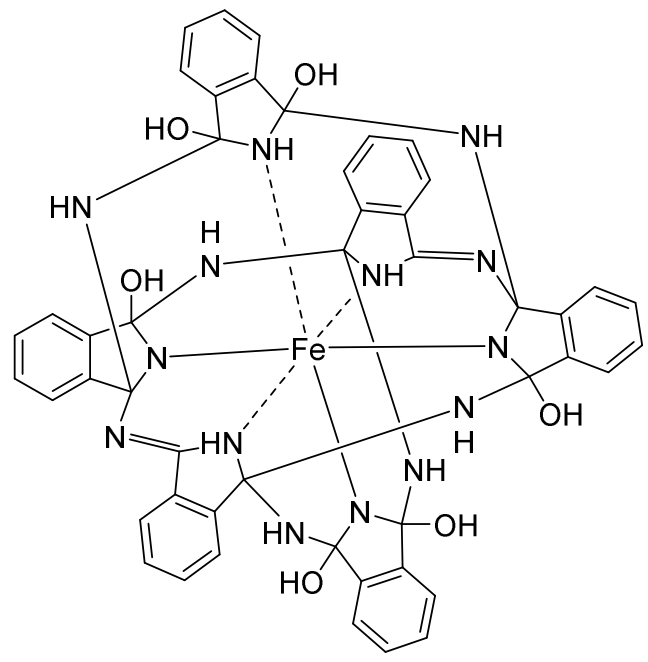

3-Fe(III)

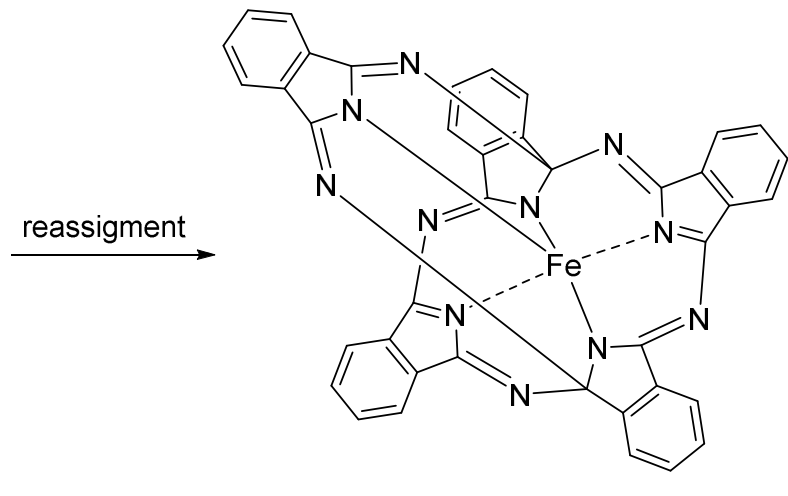

4-Fe(III)

Figure 2. Proposed structure of a hexaisoindoline 3-Fe(III) complex by Kaufmann [30] reassigned to a helmet pentadentate phthalocyanine-like 4-Fe(III) complex described by McGaff [35]. 
To support the reassignment, we also synthesized the complex according to McGaff procedure, did the same purification through silica gel chromatography, and compared the mass spectra of both samples, showing almost no differences between them (see Supporting Information). Following the measurement conditions, we noted an acetonitrile adduct once used as solvent (Figure 3) and wondered if it would occupy the sixth coordination site as ligand. However, the signal is lost by doing the HRMS measurement at higher energy, and after evaporation of the solvent under vacuum, no characteristic $\mathrm{C} \equiv \mathrm{N}$ bands in infrared spectroscopy could have been identified, suggesting a simple adduct during the measurement.

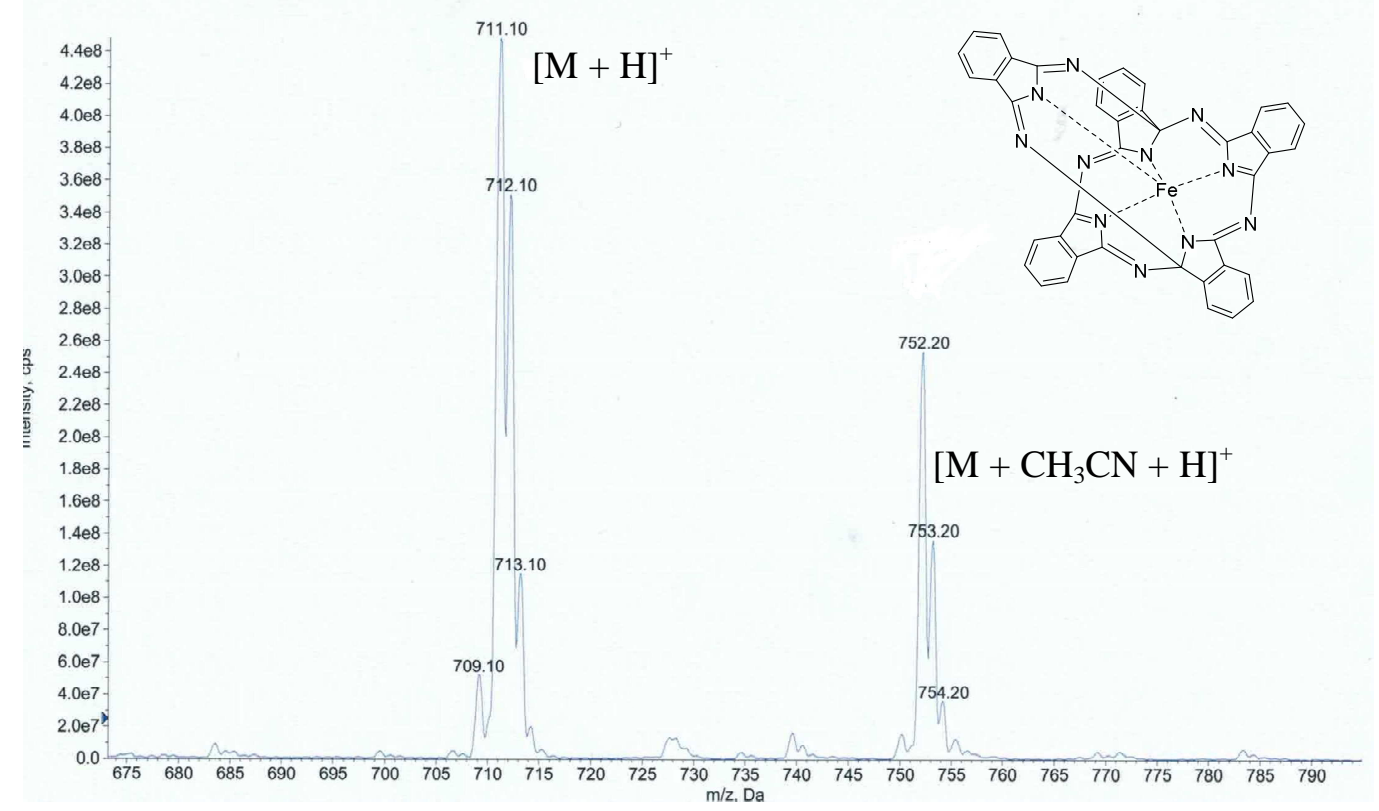

Figure 3. Isotopic distribution of the helmet pentadentate phthalocyanine-like Fe(III) complex 4-Fe(III) obtained by ESI-MS in acetonitrile

Purity of the product obtained according to Kaufmann and Slozar's procedure was however checked by measuring the iron content by atomic absorption spectroscopy and gave only a maximum of 48 wt.\% (iron content of 3.8 wt.\%). The presence of another complex cannot be ruled out by mass spectrometry due to possible differences in ionization, so visible absorbance spectra were also compared (Figure 4). 


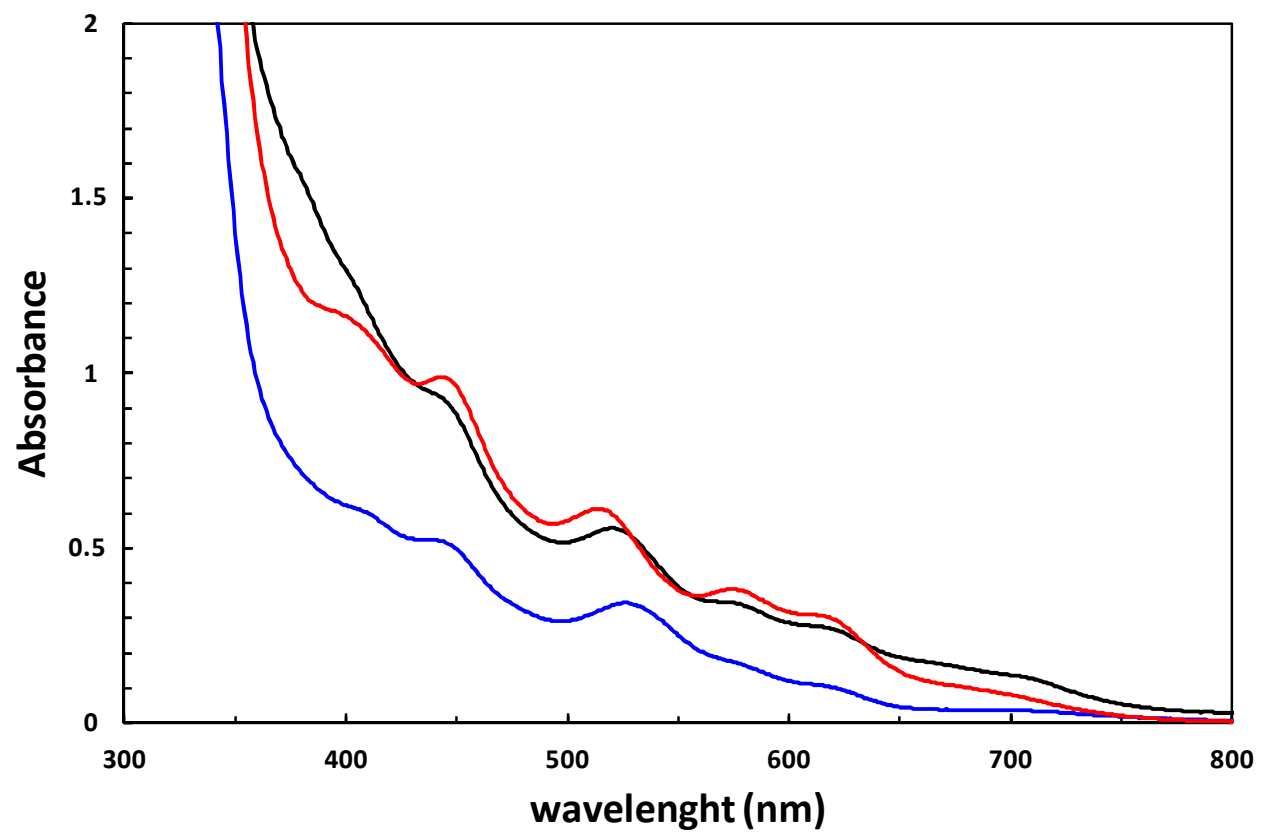

Figure 4. UV-Visible spectra at 0.2 g. $\mathrm{L}^{-1}$ in dichloromethane of 4-Fe(III) complex synthesized according to McGaff [35] after purification through silica gel chromatography (black) and according to Kaufmann and Slosar et al. procedure [30,32] before (blue) and after purification through silica gel chromatography (red).

Compared to McGaff reference sample, the spectra obtained with the unpurified product exhibit a bathochromic shift, which may be due to the presence of residual polar compounds, and a lower intensity. We thus did the same purification through silica gel chromatography and both UV-Vis spectra are almost similar. The purification yield was $51 \mathrm{mg}$ over $100 \mathrm{mg}$, supporting well the purity of 48 wt.\% determined by atomic absorption spectroscopy, but we were unable to isolate the byproducts. However, even after chromatography, the elemental analysis still not fit with the theoretical values (measured: C 64.11; H 3.54; N 19.53; theoretical: C 67.62; H 2.84; N 21.69) and the iron content is not really improved from $3.8 \mathrm{wt} . \%$ before to $4.8 \mathrm{wt} . \%$ after chromatography (theoretical: 7.86 wt.\%). This may be due to the additional presence of colloidal silica solubilized by the polar eluent during the chromatography. We thus checked if the chromatography would really improve the catalytic performances by suppressing some of the impurities. That for, we compared the oxidation of bulk soybean FAMEs at $40{ }^{\circ} \mathrm{C}$, with the sample before and after the chromatography, at a same iron content (2.5 mM, 0.014 wt.\%) taken into account their amount determined by ICP, (3.8 and 4.8 wt.\% respectively, see Supporting Information, Figure SI-6). Since the oxidation time is almost the same, 
the part of the impurities removed by chromatography does not seem to interfere in the oxidation processes.

To sum up, we concluded that both syntheses provide the same iron complex in view of the mass and visible absorbance spectra, the thin layer chromatography retardation factors, and their similarities. If the one reported by Slozar produces a less pure material, it is a more practical approach since it avoids silica gel chromatography or tedious recrystallization. We thus pursued the study with the product obtained by this procedure taken into account its iron content of $3.8 \mathrm{wt} . \%$.

\subsection{Catalysts activities on sunflower FAMEs oxidation}

Sunflower FAMEs were chosen since the composition in linoleic (57\%) and oleic acid (30\%) constitute an ideal binary mixture in point of view of their oxidation time [38]. The oxidation was carried out in the presence of $12.5 \mathrm{mM}$ of the different catalysts, 1 -Co(II), 2-Fe(II), 4-Fe(III) at $80{ }^{\circ} \mathrm{C}$ and $400 \mathrm{kPa}$ of dioxygen atmosphere (Figure 5). The amount of the catalysts was chosen according to the supplier recommendations based on dried alkyd resin content concerning 1-Co(II), which should be between 0.03-0.08 wt.\% of metal amount compared to the dried alkyd binder for conventional paint. The concentration of $12.5 \mathrm{mM}$ of $1-\mathrm{Co}(\mathrm{II})$, corresponds thus to $0.0735 \mathrm{wt} . \%$ of cobalt compared to the FAMEs, the upper limit to have comparable Co/FAMEs ratios with low oil length alkyd resin. It should be noted that Borchi ${ }^{\circledR}$ OXY-Coat 1101 is recommended to be used at 0.0006 wt.\% compared to the binder, explaining the low titration of the commercial sample (0.09 wt.\% Fe(II)). It was lyophilized before use to be able to reach $12.5 \mathrm{mM}$, giving a 0.07 wt. $\%$ concentration of iron compared to the FAMEs. 


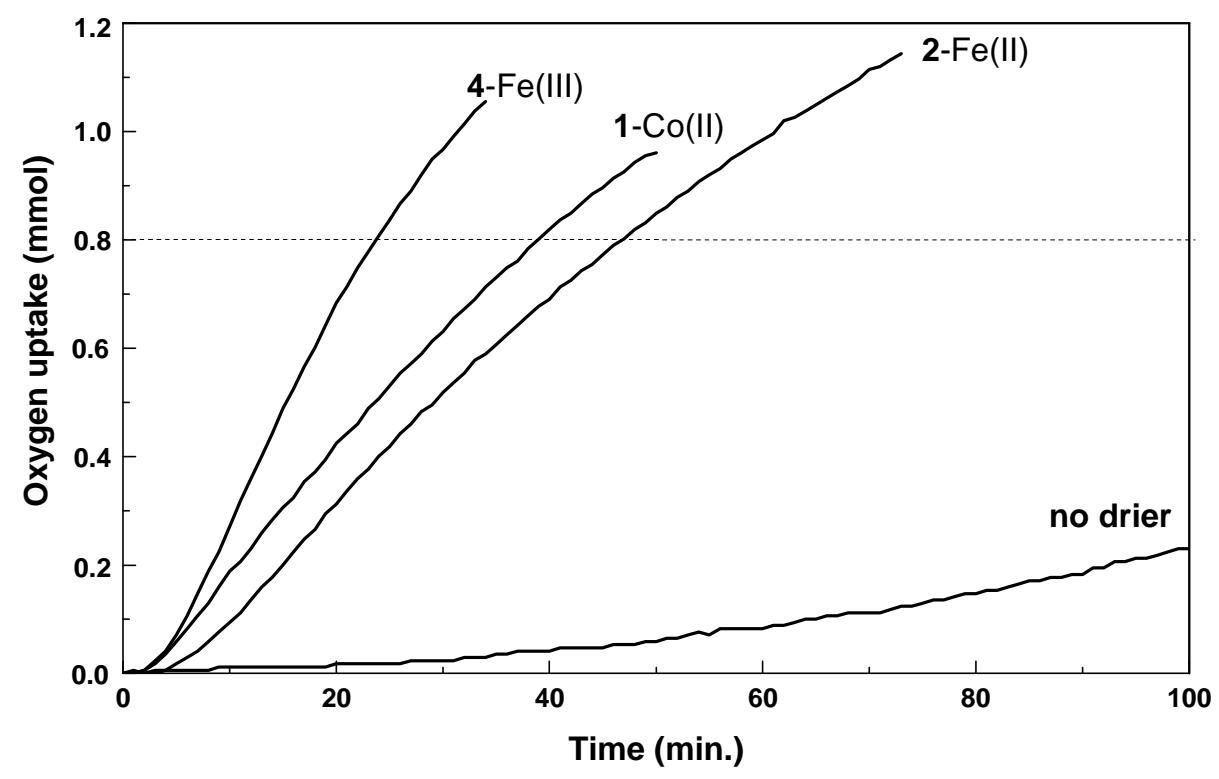

Figure 5. Oxygen uptake of the sunflower FAMEs $(2 \mathrm{~mL}, 5.9 \mathrm{mmol})$ in the presence of $12.5 \mathrm{mM}$ of 1-Co(II), 2$\mathrm{Fe}(\mathrm{II})$ and $4-\mathrm{Co}(\mathrm{III})$ in the RapidOxy ${ }^{\circledR}\left(\mathrm{T}=80^{\circ} \mathrm{C}, \mathrm{P}_{\mathrm{abs}}=400 \mathrm{kPa}\right)$.

Like for cobalt, both iron catalysts exhibit an initiation time, but the catalyst phthalocyanine-like 4$\mathrm{Fe}$ (III) catalyzes the oxidation much faster afterwards. A decrease in oxidation rate is observed after $0.8 \mathrm{mmol}$ of dioxygen consumption, which corresponds to $15 \%$ of conversion of the unsaturated part of the sunflower FAMEs. The times required for such conversion are 24,39 and 47 minutes respectively for $4-\mathrm{Fe}(\mathrm{III}), \mathbf{1}-\mathrm{Co}(\mathrm{II})$ and $2-\mathrm{Fe}(\mathrm{II})$. Based on these promising preliminary results, we looked at the influence of the concentration of the catalysts in the same conditions and the time required for such conversion level has been compared (Figure 6, see whole oxygen uptake curves in supporting information Figures SI 8-14). 


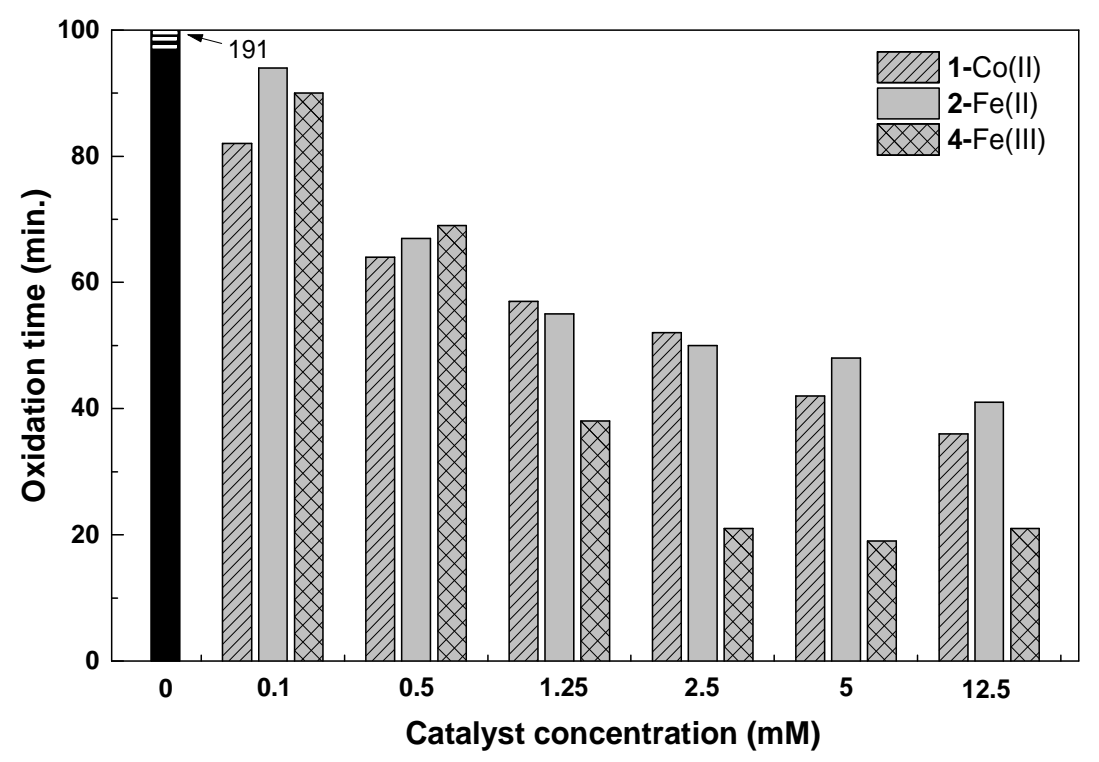

Figure 6. Oxidation time required for $0.8 \mathrm{mmol}$ of oxygen uptake during the oxidation of sunflower FAMEs (2 $\mathrm{mL}, \mathrm{n}=5.9 \mathrm{mmol}$ ) in the presence of $\mathbf{1 - C o}(\mathrm{II}), \mathbf{2}-\mathrm{Fe}(\mathrm{II})$ and 4-Fe(III) at various catalysts concentrations using RapidOxy® $\left(\mathrm{T}=80{ }^{\circ} \mathrm{C}, \mathrm{P}_{\mathrm{abs}}=400 \mathrm{kPa}\right)$.

Whereas both 1-Co(II) and 2-Fe(II) have a rather regular decrease in activity according to their concentration lowering, the phthalocyanine-like 4-Fe(III) complex keeps a very good one from 12.5 $\mathrm{mM}$ to at least $2.5 \mathrm{mM}$. However, below $0.5 \mathrm{mM}$, no clear differences can be observed between the three catalysts at such temperature. These results are however in contrast to literature data in which 2$\mathrm{Fe}$ (II) is very active at lower concentration as mentioned above. We do not believe that the lyophilization would damage the catalyst, evaporation of water being done at frozen temperature. It may rather affect the repartition of the catalyst dispersed as solid, that would limit the oxidation areas (not stirred system), or the system would be for all cases overdosed. It should be keep in mind that rather high concentration can be problematic for the coating with some driers, as shown in the literature for 2-Fe(II) [8]. The results obtained with such bulk FAME oxidation model should thus be carefully extrapolated to real systems, and should be rather used to highlight than rule out potential candidates for oxidative drying. Since $2.5 \mathrm{mM}$ appears to be a limit concentration, corresponding to nearly $0.1 \mathrm{~mol} \%$ relative to the unsaturated part of the sunflower FAMEs, the temperature effect was determined at such concentration looking at the kinetics. That for, pseudo first order kinetics were 
considered at the early stage of the oxidation after the initiation step. By plotting $\ln \left(\left[\mathrm{O}_{2}\right]_{t} /\left[\mathrm{O}_{2}\right]_{0}\right)$ from the oxygen uptakes curves as a function of time, the slopes of the linearized portions of the curves allow to determine pseudo first order rate constants $k$, which were reported according to the temperature (Figure 7).

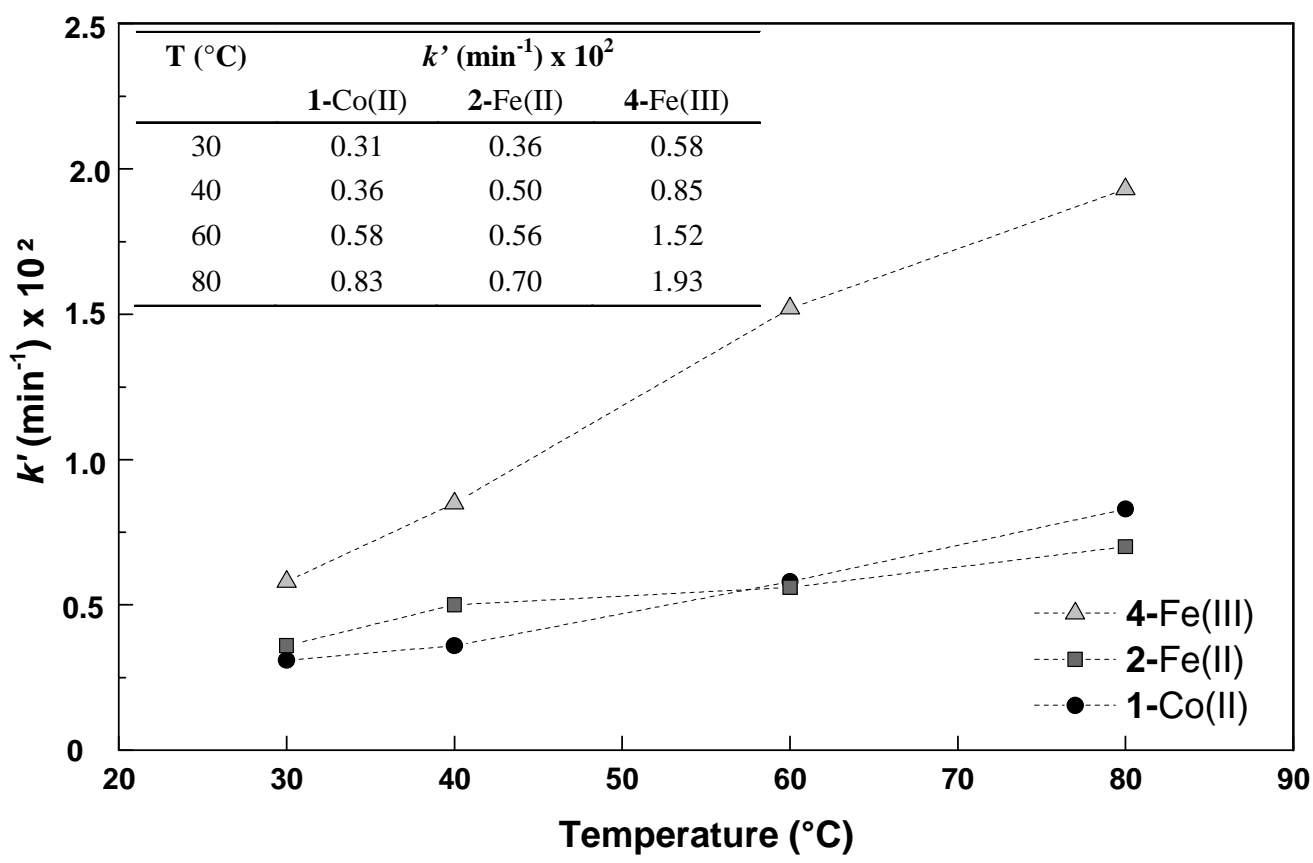

Figure 7. Pseudo- $1^{\text {st }}$-order rate constants $k\left(\mathrm{~min}^{-1}\right)$ as a function of the temperature of the oxidation of sunflower FAMEs $(2 \mathrm{~mL}, \mathrm{n}=5.9 \mathrm{mmol})$ in the presence of $2.5 \mathrm{mM}$ of $\mathbf{1}-\mathrm{Co}(\mathrm{II}), \mathbf{2}-\mathrm{Fe}(\mathrm{II})$ and $4-\mathrm{Fe}(\mathrm{III})$ in the RapidOxy ${ }^{\circledR}$ $\left(\mathrm{P}_{\mathrm{abs}}=400 \mathrm{kPa}\right)$.

The difference of the slopes of $k$ ' values along the temperatures between the two iron catalysts means that there is at least two different rate limiting steps for the oxidation process, whereas the nonlinearity observed for 1-Co(II) catalyst means a change of rate limiting step following to the temperature. It should be noted that the differences in the kinetics tend to decrease between the three catalysts by decreasing the temperature, but since the kinetics are slower, a small change implies significant overall oxidation time differences. Indeed, at $30{ }^{\circ} \mathrm{C}$, the time required for $15 \%$ conversion of the unsaturated part of sunflower FAMEs ( $0.8 \mathrm{mmol}$ of dioxygen uptake) are 78, 125 and 175 minutes for 4-Fe(III), 2-Fe(II) and 1-Co(II) respectively. Noteworthy, whereas 1-Co(II) was more 
active than 2 -Fe(II) at $80{ }^{\circ} \mathrm{C}$, their reactivity order is reversed around $60{ }^{\circ} \mathrm{C}$. However, $4-\mathrm{Fe}(\mathrm{III})$ is the most efficient catalyst whatever the temperature.

In addition to the results obtained with the RapidOxy ${ }^{\circledR}$, the oxidation reaction rate was also investigated by ATR-FTIR spectroscopy, which mimics more closely a paint film at room temperature.[39] The oxidation of sunflower FAMEs in the presence of $\mathbf{1 - C o}(\mathrm{II}), \mathbf{2}-\mathrm{Fe}$ (II) and 4$\mathrm{Fe}(\mathrm{III})$ at $12.5 \mathrm{mM}$ was followed by the disappearance of the two peaks corresponding to the stretching and bending (cis)-C=C-H at $3010 \mathrm{~cm}^{-1}$ and $723 \mathrm{~cm}^{-1}$ respectively $[19,20,40]$. The pseudo$1^{\text {st }}$-order rate constants $\left(k^{\prime}\right.$, in $\left.\mathrm{h}^{-1}\right)$ were obtained by a slope fitting the linear portions of the plotting of $\ln \left[(A)_{t} /(A)_{0} \times 100\right]$ versus time, where $(\mathrm{A})_{\mathrm{t}}$ and $(\mathrm{A})_{0}$ represent the area of peaks at time $\mathrm{t}$ and $0($ Figure 8) [41].

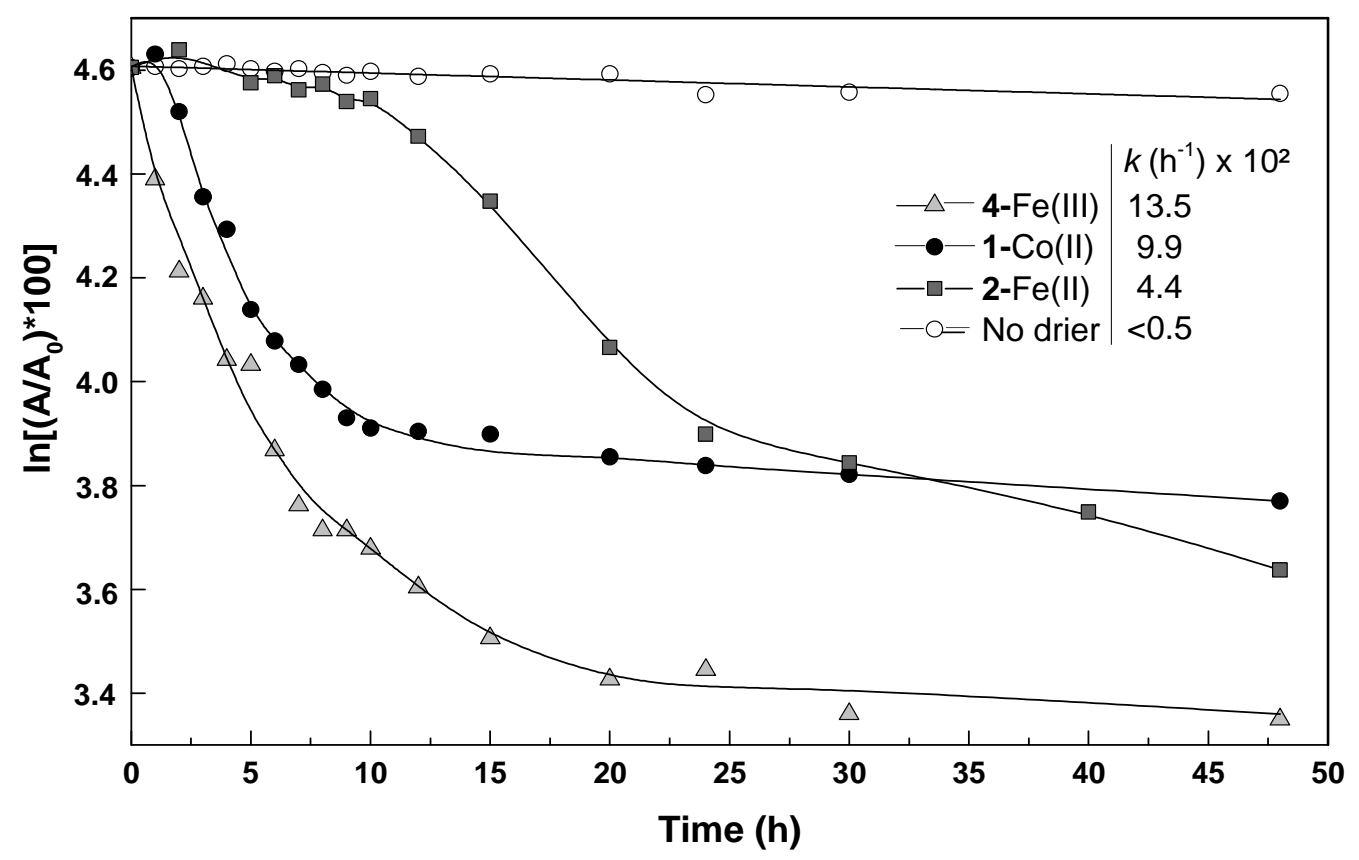

Figure 8. Plot of $\ln \left[(A)_{t} /(A)_{0} \times 100\right]$ of the $3010 \mathrm{~cm}^{-1}$ peak areas versus time of the sunflower FAMEs films (10 $\mu \mathrm{L}$ spread drops) oxidized on air in the presence of $12.5 \mathrm{mM}$ of 1-Co(II), 2-Fe(II) and 4-Fe(III) monitored by ATR-FTIR, and their corresponding pseudo- $1^{\text {st }}$-order rate constants $k$.

At atmospheric pressure and ambient temperature, the sunflower FAMEs alone oxidize very slightly over $48 \mathrm{~h}$. In presence of 2 -Fe(II) drier, after an induction period of $10 \mathrm{~h}$, a pseudo- $\mathbf{1}^{\text {st }}$-order kinetic 
can be determined up to $25 \mathrm{~h}$ with $k=0.044 \mathrm{~h}^{-1}$. With the commercial 1-Co(II) drier, a shorter induction period of one hour is observed and the rate constant is higher, however, this latter tends to be deactivated after $10 \mathrm{~h}$. Their reactivity order differs from the conclusion above in Figure $\mathbf{5}$ but is in agreement to the concentration effect reported in Figure 6. In contrast, the phthalocyanine-like 4$\mathrm{Fe}(\mathrm{III})$ complex exhibits almost no induction time together with a higher catalytic activity, with a pseudo- $1^{\text {st }}$-order rate constant 1.5 and 3 times higher than those of $\mathbf{1 - C o ( I I )}$ and 2 -Fe(II) respectively.

Whereas such model (ATR-FTIR) is closer to a paint film than bulk FAMEs, the drying of an aqueous paint emulsion may differ due to the presence of water. Even if the chemical drying normally occurs after water evaporation of the coated emulsion [42], the alkyd emulsion oxidability in bulk state would give good indications about the catalyst activity in such environment, and has thus been investigated thereafter.

\subsection{Catalytic activity of 4-Fe(III) towards the chemical drying of an alkyd resin in emulsion}

The catalyst 4-Fe(III) was studied for the oxidation of a commercial alkyd resin emulsion (URADIL AZ765 - DSM). For comparison with bulk FAMEs, its concentration was adjusted to $0.5 \mathrm{mM}$ in the emulsion, corresponding to $2.5 \mathrm{mM}$ relative to the oil content $(20 \mathrm{wt} . \%)$ of the emulsion. Figure 9 shows the oxygen uptake obtained with the StirOxy reactor at $40{ }^{\circ} \mathrm{C}$ and $150 \mathrm{kPa}$ of dioxygen.

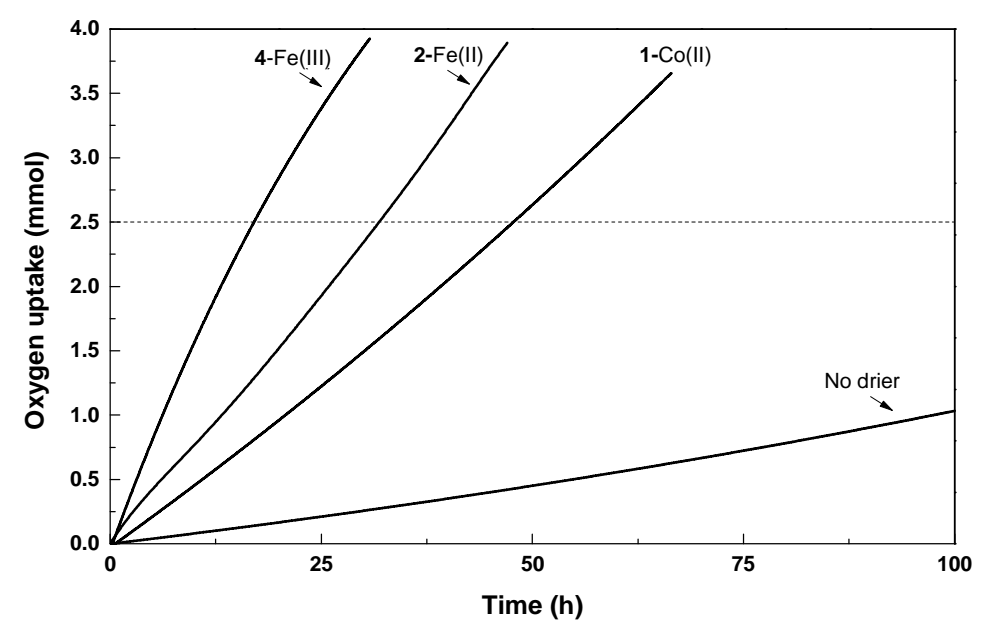

Figure 9. Oxygen uptake during the oxidation of an alkyd resin emulsion in the presence of $0.5 \mathrm{mM}$ of 1-Co(II), 2-Fe(II) and 4-Fe(III) in the StirOxy $\left(\mathrm{T}=40{ }^{\circ} \mathrm{C}, \mathrm{P}_{\mathrm{abs}}=150 \mathrm{kPa}, 250 \mathrm{rpm}\right)$. 
The same trends to the FAMEs oxidation in the RapidOxy® at low temperature were obtained, i.e. the kinetics of oxidation are faster following the order 4-Fe(III) $>$ 2-Fe(II) $>$ 1-Co(II). For an oxygen uptake of $2.5 \mathrm{mmol}$, the times required were respectively of 48,32 and 17 hours for 1-Co(II), 2-Fe(II) and 4-Fe(III), compared to a very slow autoxidation over 190 hours.

\subsection{Decomposition of methyl linoleate hydroperoxides}

To confirm the substantial activity of the phthalocyanine 4-Fe(III) complex, we have studied its ability to decompose methyl linoleate hydroperoxides, prior obtained by photooxidation as a mixture of mono- and di-hydroperoxides (see supporting information SI-9). The activity of the different catalysts was assessed by HPLC, monitoring the conversion as a function of time (Figure 10).

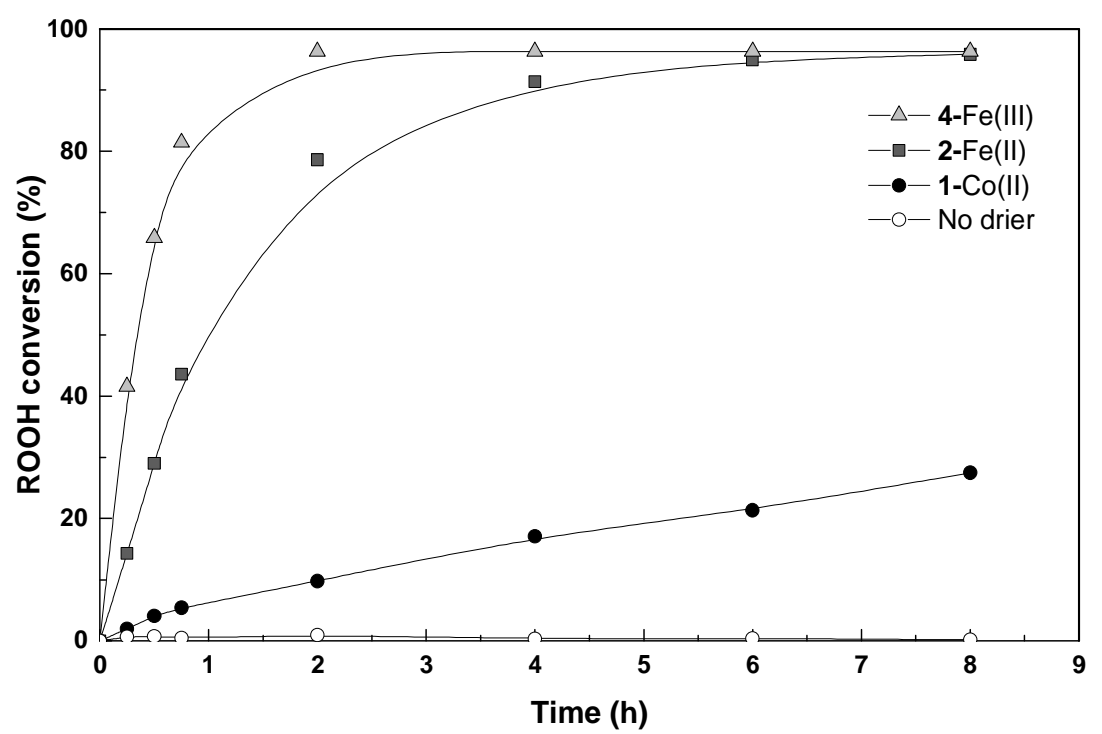

Figure 10. Decomposition of methyl linoleate hydroperoxides at $0.087 \mathrm{M}$ in BuOAc at room temperature in the presence of $0.2 \mathrm{~mol} \%$ of $\mathbf{1}-\mathrm{Co}(\mathrm{II}), \mathbf{2}-\mathrm{Fe}(\mathrm{II})$ and $\mathbf{4}-\mathrm{Fe}(\mathrm{III})$ monitored by HPLC.

The hydroperoxides do not decompose alone within $8 \mathrm{~h}$ at room temperature, while in the presence of the iron catalysts, the conversion is almost complete. Noteworthy, with the phthalocyanine-like 4$\mathrm{Fe}(\mathrm{III})$ complex, the reaction is faster with a final conversion (95\%) reached after only $2 \mathrm{~h}$ against $6 \mathrm{~h}$ 
with 2-Fe(II). In contrast, the 1-Co(II) drier decomposes only $30 \%$ of the hydroperoxides over $8 \mathrm{~h}$ under the same conditions. Like for FTIR experiments, pseudo- $1^{\text {st }}$-order rate constants can be extracted from the data by plotting $\ln \left([\mathrm{ROOH}]_{t} /[\mathrm{ROOH}]_{0}\right)$ as a function of time (see supporting information Figure SI-7). According to Hermans et al. [43], deviation from the linearity was expected in case of 1-Co(II), that would means the deactivation of the catalyst, but this was not clearly observed in our conditions, except for 2 -Fe(II). The pseudo first order constants were determined as 22.4, 7.9 and $0.4 \mathrm{~h}^{-1}$ for 4-Fe(III), 2-Fe(II) and 1-Co(II) respectively.

In contrast to the air-oxidation of sunflower FAMEs film measured by ATR-FTIR, no induction period was observed. The high reactivity of the iron-based catalysts during the decomposition of hydroperoxides is related to the Fenton type reactions to form active radical species such as alkoxy and peroxy radicals (Eq. 1 and 2) [44-46].

$$
\begin{aligned}
& \mathrm{ROOH}+\left[\mathrm{Fe}^{\mathrm{II}}\right] \rightarrow \mathrm{RO}^{\bullet}+\mathrm{HO}^{-}+\left[\mathrm{Fe}^{\mathrm{III}}\right] \\
& \mathrm{ROOH}+\left[\mathrm{Fe}^{\mathrm{III}}\right] \rightarrow \mathrm{ROO}^{\bullet}+\mathrm{H}^{+}+\left[\mathrm{Fe}^{\mathrm{II}}\right]
\end{aligned}
$$

Some similarities can be made with metabolic reactions concerning lipid peroxidation [47]. Thus, by a biomimetic approach, the porphyrin Fe(III) complexes are generally used to evaluate the decomposition of hydroperoxides into active radical species RO [48-50]. The action of the phthalocyanine-derived 4-Fe(III) complex would rather involves the formation of an iron-oxo intermediate [36]. Concerning the kinetics, 1-Co(II) has a rate of hydroperoxide decomposition 20 and 60 times lower compared respectively to 2 -Fe(II) and $4-\mathrm{Fe}$ (III). However, the oxidation rates of bulk sunflower FAMEs remain 2 times faster with 1-Co(II) than with 2-Fe(II). Since the solvent effects have been minimized by choosing butyl acetate for the decomposition of the peroxides, this indicates that it would not be the determining step in the oxidation of the sunflower FAMEs.

\subsection{Hardness and coloration of the coating film of a white satin paint}

Finally, the three catalysts 1-Co(II), 2-Fe(II) and 4-Fe(III) were tested at the same catalytic amounts ( $2.5 \mathrm{mM}$ related to the oil content of the emulsion) for applicative drying tests of a satin white coating composed of the same alkyd resin URADIL AZ765 studied above alone in emulsion. This corresponds 
to 0.0395 wt. $\%$ of Co and 0.0375 wt.\% of Fe compared to the dried alkyd binder. Table 1 shows the hardness values measured by a Persoz pendulum and the color values $\left(\mathrm{L}^{*}, \mathrm{a}^{*}, \mathrm{~b}^{*}\right)$ of the films collected by spectrophotometry after 3 weeks. After that time, the specifications of coating hardness should be between 70 and 120 seconds and the $a^{*}$ and $b^{*}$ values closed to 0 for a white film.

Table 1. Persoz hardness (oscillations expressed in seconds) and coloration of a white satin coating in the presence of 1-Co(II), 2-Fe(II) and 4-Fe(III) after 3 weeks of drying.

\begin{tabular}{lcc}
\hline Drier $(\mathbf{2 5} \boldsymbol{\mu m o l})$ & Persoz hardness $(\mathbf{s})^{*}$ & $\mathbf{L}^{*}, \mathbf{a}^{*}, \mathbf{b}^{*}$ \\
\hline $\mathbf{1 - C o}(\mathrm{II})$ & 81 & $94.13 ;-1.09 ;-0.52$ \\
$\mathbf{2}-\mathrm{Fe}(\mathrm{II})$ & 111 & $93.72 ;-1.79 ; 4.00$ \\
4-Fe(III) & 97 & $92.02 ;-1.27 ; 0.90$ \\
\hline of the glass support corresponds to $430 \mathrm{~s}$. &
\end{tabular}

* The hardness value of the glass support corresponds to $430 \mathrm{~s}$.

By comparing the different catalysts, the higher hardness results are obtained with 2-Fe(II) (111 s), closely followed by $4-\mathrm{Fe}(\mathrm{III})$ (97 s) and finally $\mathbf{1 - C o ( I I )}$ (81s), all in accordance with the specifications. However, even if 2-Fe(II) gives a slightly higher value of hardness compared to 4$\mathrm{Fe}(\mathrm{III})$, the yellowing $\left(\mathrm{b}^{*}\right)$ induced by this latter is four times lower, which can be advantageous for some applications.

\section{Experimental part}

Commercial driers Octa-Soligen ${ }^{\circledR}$ Cobalt 10 (10 wt.\% cobalt(II) bis(2-ethylhexanoate 1-Co(II)), OctaSoligen® Cobalt 7 aqua (7 wt.\% Co(II) bis(2-ethylhexanoate)), Borchi® OXY-Coat 1101 (0.09 wt.\% $\mathrm{Fe}(\mathrm{II}))$ were generously provided by OMG Borchers. Borchi® OXY-Coat 1101 was lyophilized before use to get 2-Fe(II) and to allow to do solutions at higher concentration of catalyst.

Octa-Soligen ${ }^{\circledR}$ Cobalt 10 was used as siccative for bulk FAMEs oxidation and peroxide decomposition in butyl acetate and was diluted in white spirit before use, whereas Octa-Soligen ${ }^{\circledR}$ Cobalt 7 aqua was used for emulsion oxidation and in the paint. Lyophilized Borchi® OXY-Coat 1101 and the synthesized 4-Fe(III) were directly dispersed as a solid.

Additional details on the materials, the synthesis and characterization of the FAMEs composition of 
sunflower oil, and the synthesis of methyl linoleate hydroperoxides by photooxidation, are given in the supporting information.

\subsection{Synthesis of 3-Fe(III) into 4-Fe(III).}

A $500 \mathrm{~mL}$ two-necked flask equipped with a big magnetic stirrer and surrounded by a Dean-Stark apparatus was filled with $\mathrm{Fe}^{\mathrm{III}}\left(\mathrm{NH}_{4}\right)_{2}\left(\mathrm{SO}_{4}\right)_{2} .12 \mathrm{H}_{2} \mathrm{O}$ (12.5 mmol, $\left.6.03 \mathrm{~g}\right)$, urea (112.5 mmol, $\left.6.76 \mathrm{~g}\right)$, ammonium nitrate $(12.5 \mathrm{mmol}, 1.00 \mathrm{~g})$, molybdenum oxide $(1.25 \mathrm{mmol}, 0.18 \mathrm{~g})$, nitrobenzene (250 $\mathrm{mL})$ then diiminoisoindoline $(125 \mathrm{mmol}, 18.15 \mathrm{~g})$ under stirring. The solution was stirred at $160{ }^{\circ} \mathrm{C}$ for 10 hours under a slight stream of air. Nitrobenzene was then distilled under vacuum $\left(5.10^{-2} \mathrm{mbar}\right)$. The black solid residue was stirred in $\mathrm{CHCl}_{3}(400 \mathrm{~mL})$ for 16 hours and the solution was filtered by gravity through filter paper. Solvents were evaporated, and the residue was dissolved in DCM (150 $\mathrm{mL})$. The product was precipitated by portion-wise addition of petroleum ether $(450 \mathrm{~mL})$, filtered under vacuum using fritted glass, washed with petroleum ether $(2 \times 100 \mathrm{~mL})$ and finally dried to get a dark-brown powder $(8.3 \mathrm{~g})$ slightly electrostatic. The product was used without further purifications considering 48 wt.\% of 4-Fe(III) according to atomic absorption spectroscopy.

Part of the sample can be purified through silica gel chromatography using $95 / 5 \mathrm{DCM} / \mathrm{MeOH}$ as eluant $(\mathrm{R} f=0.4)$, giving $51 \mathrm{mg}$ of $4-\mathrm{Fe}(\mathrm{III})$ starting from $100 \mathrm{mg}$.

\subsection{Catalysts activities on sunflower FAMEs oxidation}

Oxygen uptake measurement was used to monitor the oxidation of FAMEs using RapidOxy ${ }^{\circledR}$ device (Anton Paar), which allows to oxidize compounds in a constant volume up to $800 \mathrm{kPa}$ of dioxygen, between 25 and $200{ }^{\circ} \mathrm{C}$. All assays were performed three times and the method showed good repeatability $(<10 \%$ standard deviation) for the limit of $50 \%$ of conversion of oxygen.

The amount of siccative was adjusted following the targeted concentration. For instance, $25 \mu \mathrm{mol}$ of siccative was added in $2 \mathrm{~mL}$ of sunflower FAMEs $(\mathrm{n}=5.9 \mathrm{mmol})$ to get $12.5 \mathrm{mM}$ concentrations, 
corresponding to $148 \mu \mathrm{L}$ of a solution of Octa-Soligen ${ }^{\circledR}$ Cobalt 10 diluted by 10 fold in white spirit, $16 \mathrm{mg}$ of lyophilized Borchi ${ }^{\circledR}$ OXY-Coat 1101, and $40 \mathrm{mg}$ of $4-\mathrm{Fe}(\mathrm{III})$ at $48 \mathrm{wt} . \%$.

\subsection{Catalytic activity of 4-Fe(III) towards the chemical drying of an alkyd resin in emulsion}

A home-made glass reactor, called StirOxy, was also developed to obtain a complementary device to the RapidOxy ${ }^{\circledR}$ (see supporting information). It has the following advantages: a larger reactor volume $(160 \mathrm{~mL})$ and the absence of pressure drop instructions enabling to achieve higher substrate conversions, a temperature-controlled glass reactor via a double layer supplied by a thermostat $(-25$ to $150^{\circ} \mathrm{C}$ ), and a magnetic stirrer which can homogenize the sample. The emulsion used was URADIL AZ765 from DSM and reactions were done under stirring.

\subsection{Decomposition of methyl linoleate hydroperoxides}

$30 \mathrm{mg}$ of a mixture of mono- and di-hydroperoxides of methyl linoleate (59 and $41 \%$ respectively) were dissolved in $1 \mathrm{~mL}$ of butyl acetate followed by the addition of the catalysts $(0.2 \mathrm{~mol} . \%)$. HPLC samples were taken at different time intervals over $25 \mathrm{~h}$ : $50 \mu \mathrm{L}$ of the sample were diluted in $2 \mathrm{~mL}$ of a standard solution of butylbenzene in acetonitrile $(0.7 \mathrm{mM})$. The mixtures were filtered through a short pad of silica to remove the catalysts before analysis.

\subsection{Hardness and coloration of the coating film of a white satin paint}

Tests were performed using a paint composed of $70 \%$ of URADIL AZ765 - DSM emulsion (characterized by $53.3 \%$ of solid content and $40 \mathrm{wt} . \%$ of oil in the resin), and titanium dioxide at 21.5\% Pigment Volume Concentration. For the drying tests, the coating was applied on a glass plate with a $150 \mu \mathrm{m}$ BYK applicator and the hardness was tested with a Persoz pendulum according to ISO 1522 standard. This method is based on the oscillations damping property related to the hardness of the film. Therefore, the oscillations will increase with the hardness of the paint film. 
Evaluation of the dried coating film colors were measured on dedicated cardboard by reflection using a Datacolor CHECK 3 portable spectrophotometer $\left(\mathrm{d} / 8^{\circ}\right.$ measuring geometry, D65 standard illuminant, pulsed xenon flash lamp source, CIELAB system). In the CIELAB system in spectrophotometry, the $L^{*}$ axis represents the lightness ( $L^{*}$ varies from 100 for white to 0 for black), and $a^{*}$ and $b^{*}$ are the chromaticity coordinates $\left(+a^{*}\right.$ is for red, $-a^{*}$ for green, $+b^{*}$ for yellow, $-b^{*}$ for blue). CIELAB $L^{*}, a^{*}, b^{*}$ parameters were measured at 3 locations on each coating and average value was automatically calculated.

\section{Conclusion}

Though already described by Kaufmann and Slosar et al., the characterization of the proposed hexaisoindoline Fe(III) complex by mass spectrometry revealed a helmet pentadentate phthalocyaninelike Fe(III) structure. The oxidative catalytic activity of this complex was compared to the two commonly used driers cobalt carboxylate 1-Co(II) and iron bispidone 2-Fe(II). The first evaluations of the sunflower FAMEs oxidation in the RapidOxy ${ }^{\circledR}$ were very conclusive, the catalyst surpassing by far the performances of both of them at low optimized catalytic concentration of $2.5 \mathrm{mM}$. Despite that the kinetics are more dependent of the temperature with this catalyst, it keeps the highest activity at room temperature and in aqueous environment as checked with the oxidation of an alkyd resin emulsion. One of the reasons may be its ability to decompose the methyl linoleate hydroperoxides much faster than the two other ones, even if it should not be the determining step. Once used in a white satin paint formulation, it provided very good results in terms of hardness, and more interestingly, poor yellowing. Therefore, this pentadentate phthalocyanine-like iron(III) complex appears as a promising alternative to cobalt driers for the chemical drying of alkyd coatings.

\section{Acknowledgements}

The Institut Français des Matériaux Agro-Sourcés, Chevreul Institute (FR 2638), Ministère de l'Enseignement Supérieur et de la Recherche, Région Nord-Pas de Calais and FEDER are 
acknowledged for supporting and funding this work. This project has been granted by the French State under the "Programme d'Investissements d'Avenir" Program (reference number: ANR-10-IEED0004-01). The authors want to thank Mr. Mike Ortega Vaz, Mrs. Céline Delabre, engineer assistants for their help during the experiments, Mr. Xavier Lemaire, engineer at Mader Colors for coatings applications and hardness/yellowing measurements, Mostafa Kouach and Christophe Penverne for mass spectrometry analysis, as well as Mrs. Marion Fressancourt-Collinet and Mr. Laurent Thomas for general discussions. Elementary analyses were performed at the Institut des Sciences Analytiques, UMR 5280, Villeurbanne.

\section{References}

1. Grau, M.; Britovsek, G.J.P. High-valent iron in biomimetic alkane oxidation catalysis. Top. Organomet. Chem. 2015, 50, 145-171.

2. Sun, C.-L.; Li, B.-J.; Shi, Z.-J. Direct C-H transformation via iron catalysis. Chem. Rev. 2011, $111,1293-1314$.

3. Gormisky, P.E.; White, M.C. Catalyst-controlled aliphatic C-H oxidations with a predictive model for site-selectivity. J. Am. Chem. Soc. 2013, 135, 14052-14055.

4. Ribeiro, A.P.C.; Martins, L.M.D.R.S.; Pombeiro, A.J.L. $\mathrm{N}_{2} \mathrm{O}$-free single-pot conversion of cyclohexane to adipic acid catalysed by an iron(II) scorpionate complex. Green Chem. 2017, 19, 1499-1501.

5. van Gorkum, R.; Bouwman, E. The oxidative drying of alkyd paint catalysed by metal complexes. Coord. Chem. Rev. 2005, 249, 1709-1728.

6. Dubrulle, L.; Lebeuf, R.; Thomas, L.; Fressancourt-Collinet, M.; Nardello-Rataj, V. Catalytic activity of primary and secondary driers towards the oxidation and hydroperoxide decomposition steps for the chemical drying of alkyd resin. Prog. Org. Coat. 2017, 104, 141151.

7. Simonsen, L.O.; Harbak, H.; Bennekou, P. Cobalt metabolism and toxicology-a brief update. Sci. Total Environ. 2012, 432, 210-215.

8. de Boer, J.W.; Wesenhagen, P.V.; Wenker, E.C.M.; Maaijen, K.; Gol, F.; Gibbs, H.; Hage, R. The quest for cobalt-free alkyd paint driers. Eur. J. Inorg. Chem. 2013, 2013, 3581-3591.

9. Hofland, A. Alkyd resins: From down and out to alive and kicking. Prog. Org. Coat. 2012, 73, 274-282.

10. Greimel, K.J.; Perz, V.; Koren, K.; Feola, R.; Temel, A.; Sohar, C.; Herrero Acero, E.; Klimant, I.; Guebitz, G.M. Banning toxic heavy-metal catalysts from paints: Enzymatic crosslinking of alkyd resins. Green Chem. 2013, 15, 381-388.

11. Hage, R.; de Boer, J.; Maaijen, K. Manganese and iron catalysts in alkyd paints and coatings. Inorganics 2016, 4, 11.

12. Preininger, O.; Charamzová, I.; Vinklárek, J.; Císařová, I.; Honzíček, J. Oxovanadium(IV) complexes bearing substituted pentane-2,4-dionate ligands: Synthesis, structure and drying activity in solvent-borne alkyd paints. Inorg. Chim. Acta 2017, 462, 16-22.

13. Clauwaert, E.; Rondas, F. Manganese based catalytic dryer for polymer coatings. WO2012000934A1, 2012.

14. Warzeska, S.T.; Zonneveld, M.; van Gorkum, R.; Muizebelt, W.J.; Bouwman, E.; Reedijk, J. The influence of bipyridine on the drying of alkyd paints: A model study. Prog. Org. Coat. 2002, 44, 243-248.

15. Lima, G.E.S.; Nunes, E.V.; Dantas, R.C.; Meneghetti, M.R.; Meneghetti, S.M.P. Systematic investigation of the oxidative polymerization of linseed oil catalyzed by $\mathrm{Co}$ (II), $\mathrm{Mn}$ (II), and 
Fe(II) complexes with chelating nitrogen ligands. Eur. J. Lipid Sci. Technol. 2015, 117, 229234.

16. Van Gorkum, R.; Bouwman, E.; Reedijk, J. Fast autoxidation of ethyl linoleate catalyzed by $\left[\mathrm{Mn}(\mathrm{acac})_{3}\right]$ and bipyridine: A possible drying catalyst for alkyd paints. Inorg. Chem. 2004, $43,2456-2458$.

17. Oyman, Z.O.; Ming, W.; Van der Linde, R.; Van Gorkum, R.; Bouwman, E. Effect of $\left[\mathrm{Mn}(\mathrm{acac})_{3}\right]$ and its combination with 2,2'-bipyridine on the autoxidation and oligomerization of ethyl linoleate. Polymer 2005, 46, 1731-1738.

18. Boomgaard, R.E.; Schier, H.; Kirchner, E.J.J.; Klaasen, R.P.; Hartl, F.; Van Der Leeuw, R.P.C.; Bakkeren, F.J.A.D. Oxidatively drying coating compositions. WO2003029371A1, 2003.

19. Micciche, F.; Van Haveren, J.; Oostveen, E.; Ming, W.; Van der Linde, R. Oxidation and oligomerization of ethyl linoleate under the influence of the combination of ascorbic acid 6palmitate/iron-2-ethylhexanoate. Appl. Catal., A 2006, 297, 174-181.

20. Micciche, F.; Long, G.J.; Shahin, A.M.; Grandjean, F.; Ming, W.; van Haveren, J.; van der Linde, R. The combination of ascorbic acid 6-palmitate and $\left[\mathrm{Fe}(\mathrm{III})_{3}\left(\mu_{3}-\mathrm{O}\right)\right]^{7+}$ as a catalyst for the oxidation of unsaturated lipids. Inorg. Chim. Acta 2007, 360, 535-545.

21. Oyman, Z.O.; Ming, W.; Micciché, F.; Oostveen, E.; van Haveren, J.; van der Linde, R. A promising environmentally-friendly manganese-based catalyst for alkyd emulsion coatings. Polymer 2004, 45, 7431-7436.

22. Oyman, Z.O.; Ming, W.; Van der Linde, R. Catalytic activity of a dinuclear manganese complex (MnMeTACN) on the oxidation of ethyl linoleate. Appl. Catal., A 2007, 316, 191196.

23. Meijer, M.D.; Van Weelde, E.; Van Dijk, J.T.M.; Flapper, J. Drier for auto-oxidizable coating composition. WO2013092442A1, 2013.

24. Erben, M.; Vesely, D.; Vinklarek, J.; Honzicek, J. Acyl-substituted ferrocenes as driers for solvent-borne alkyd paints. J. Mol. Catal. A: Chem. 2012, 353-354, 13-21.

25. Hage, R.; Gol, F.; Gibbs, H.W.; Maaijen, K. Antiskinning compositions for coatings. WO2012093250A1, 2012.

26. Weijnen, J.; Klomp, D. Modified alkyd resins and use in coatings. WO2013045475A1, 2013.

27. Hage, R.; Wesenhagen, P.V. Curing catalysts for air drying inks and coatings with fast curability. WO2008003652A1, 2008.

28. Kaufmann, H.P. Catalysts for the polymerization of unsaturated organic compounds. DE1128659, 1962.

29. Kaufmann, H.P. Pro- and antioxidants for fats. XI. The effect of iron porphyrins on the autoxidation of polyenes. Fette, Seifen, Anstrichm. 1964, 66, 743-749.

30. Kaufmann, H.P.; Fleiter, L. Pro- and antioxidants for fats. XII. Heavy-metal complexes as prooxidants. 3. Iron complexes of a hydroxylated porphyrazine. Fette, Seifen, Anstrichm. 1964, 66, 819-824.

31. Santhanam, R. Additives for curable liquid compositions, compositions that include siccatives, as well as making and using the siccatives. US20120165435A1, 2012.

32. Slosar, P.; Necas, M.; Rejlek, A. Hexaisoindoline-iron complex. CS224818B1, 1984.

33. Jarusek, J.; Slosar, P. Initiation of radical formation with a hexaisoindoline iron complex. $S b$. Ved. Pr., Vys. Sk. Chemickotechnol. Pardubice 1985, 48, 237-244.

34. Jarusek, J.; Slosar, P. Suitability of a hexaisoindoline iron complex as a siccative. Sb. Ved. Pr., Vys. Sk. Chemickotechnol. Pardubice 1986, 49b, 381-390.

35. Kieler, H.M.; Bierman, M.J.; Guzei, I.A.; Liska, P.J.; McGaff, R.W. Racemic iron(III) and cobalt(III) complexes containing a new pentadentate "helmet" phthalocyaninato ligand. Chem. Commun. 2006, 3326-3328.

36. Skobelev, I.Y.; Kudrik, E.V.; Zalomaeva, O.V.; Albrieux, F.; Afanasiev, P.; Kholdeeva, O.A.; Sorokin, A.B. Efficient epoxidation of olefins by $\mathrm{H}_{2} \mathrm{O}_{2}$ catalyzed by iron "helmet" phthalocyanines. Chemical Commun. 2013, 49, 5577-5579.

37. Neve, R.L.; Eidenschink, M.C.; Guzei, I.A.; Peterson, B.M.; Vang, G.M.; McGaff, R.W. Homogeneous catalytic oxidation of unactivated primary and secondary alcohols employing a 
versatile "helmet" phthalocyaninato iron complex catalyst without added organic solvent. ChemistrySelect 2016, 1, 5182-5186.

38. Dubrulle, L.; Lebeuf, R.; Fressancourt-Collinet, M.; Nardello-Rataj, V. Optimization of the vegetable oil composition in alkyd resins: A kinetic approach based on fames autoxidation. Prog. Org. Coat. 2017, 112, 288-294.

39 Charamzová, I.; Vinklárek, J.; Jan Honzíček, J. Effect of primary driers on oxidative drying of high-solid alkyd binder: Investigation of thickness effects by mechanical tests and infrared Spectroscopy. Prog. Org. Coat. 2018, 125, 177-185.

40. Mallegol, J.; Lemaire, J.; Gardette, J.L. Drier influence on the curing of linseed oil. Prog. Org. Coat. 2000, 39, 107-113.

41. Warzeska, S.T.; Zonneveld, M.; van Gorkum, R.; Muizebelt, W.J.; Bouwman, E.; Reedijk, J. The influence of bipyridine on the drying of alkyd paints: A model study. Prog. Org. Coat. 2002, 44, 243-248.

42. Okan Oyman, Z.; Ming, W.; van der Linde, R. Oxidation of model compound emulsions for alkyd paints under the influence of cobalt drier. Prog. Org. Coat. 2003, 48, 80-91.

43. Spier, E.; Neuenschwander, U.; Hermans, I. Insights in the cobalt(II)-catalyzed decomposition of peroxide. Angew. Chem., Int. Ed. 2013, 52, 1581-1585.

44. Fenton, H.J.H. Oxidation of tartaric acid in presence of iron. J. Chem. Soc., Trans. 1894, 65, 899-910.

45. Masarwa, A.; Rachmilovich-Calis, S.; Meyerstein, N.; Meyerstein, D. Oxidation of organic substrates in aerated aqueous solutions by the fenton reagent. Coord. Chem. Rev. 2005, 249, 1937-1943.

46. Haber, F.; Weiss, J. The catalytic decomposition of hydrogen peroxide by iron salts. Proc. $R$. Soc. London, Ser. A 1934, 147, 332-351.

47. Sergent, O.; Morel, I.; Cillard, J. Involvement of metal ions in lipid peroxidation: Biological implications. Met. Ions Biol. Syst. 1999, 36, 251-287.

48. Nam, W.; Han, H.J.; Oh, S.-Y.; Lee, Y.J.; Choi, M.-H.; Han, S.-Y.; Kim, C.; Woo, S.K.; Shin, $\mathrm{W}$. New insights into the mechanisms of $\mathrm{O}-\mathrm{O}$ bond cleavage of hydrogen peroxide and tertalkyl hydroperoxides by iron(III) porphyrin complexes. J. Am. Chem. Soc. 2000, 122, 86778684.

49. Traylor, T.G.; Xu, F. A biomimetic model for catalase: The mechanisms of reaction of hydrogen peroxide and hydroperoxides with iron(III) porphyrins. J. Am. Chem. Soc. 1987, 109, 6201-6202.

50. Davies, M.J.; Gammon, R.E.; Lindsay Smith, J.R.; Lower, R.J. Reaction of iron(III) tetra(4-Nmethylpyridyl)porphyrin with tertiary-butyl hydroperoxide in aqueous solution. In Stud. Surf. Sci. Catal., Simándi, L.I., Ed. 1991; Vol. 66, pp 297-303. 
Cross-linking $=$ Oxidative

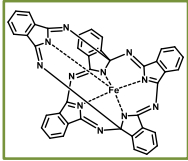

Phthalocyanine-derivated Fe(III) complex

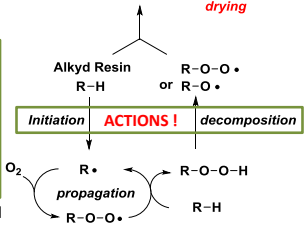

